
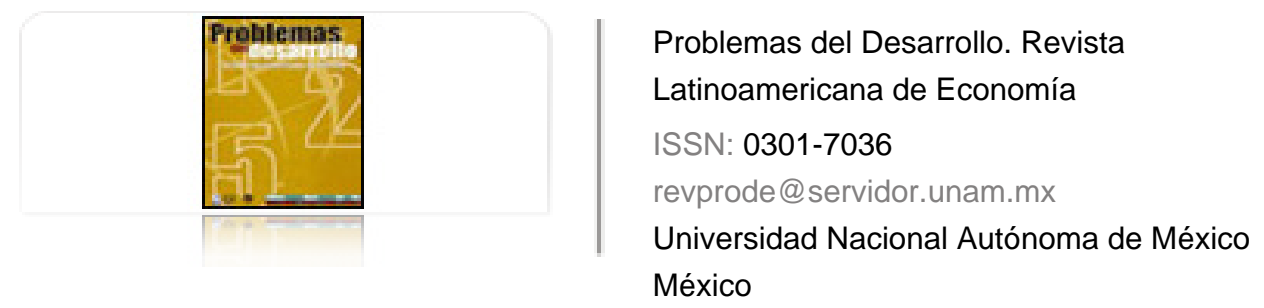

Piégay, Pierre; Rochon, Louis-Philippe

Teorías monetarias poskeynesianas: una aproximación de la escuela francesa Problemas del Desarrollo. Revista Latinoamericana de Economía, vol. 36, núm. 143, octubre-

diciembre, 2005, pp. 33-57

Universidad Nacional Autónoma de México

Distrito Federal, México

Disponible en: http://www.redalyc.org/articulo.oa?id=11820081003

Cómo citar el artículo

- Número completo

- Más información del artículo

Página de la revista en redalyc.org

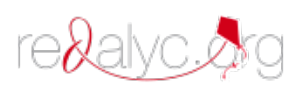

Sistema de Información Científica

Red de Revistas Científicas de América Latina, el Caribe, España y Portugal Proyecto académico sin fines de lucro, desarrollado bajo la iniciativa de acceso abierto 


\section{TEORÍAS MONETARIAS POSKEYNESIANAS: UNA APROXIMACIÓN DE LA ESCUELA FRANCESA}

\section{Pierre Piégay* Louis-Philippe Rochon**}

Fecha de recepción: 28 de febrero de 2005. Fecha de aceptación: 26 de octubre de 2005.

\section{Resumen}

Este texto es una presentación sintética de las características esenciales de las teorías monetarias poskeynesianas. Deseamos mostrar que, en el marco institucional actual, éstas constituyen una herramienta útil para aprehender el funcionamiento de nuestras economías monetarias. Al descomponer las relaciones entre las esferas financiera y productiva, los poskeynesianos justifican la necesidad de promover una regulación monetaria y financiera. En el análisis se ve con claridad que la política monetaria no debe estar exclusivamente dedicada a la lucha contra la inflación, además de que el gran desentendimiento del Estado no deja exenta de riesgos a la estabilidad del sistema en su totalidad.

Palabras clave: moneda endógena, sistema bancario, tasa de interés, teorías monetarias post-keynesianas.

\section{Abstract}

This text is a synthetic presentation of the essential characteristics of post-Keynesian monetary theories. We wish to show that, in the current institutional framework, they constitute a useful instrument for understanding the functioning of our monetary economics. By breaking down the relations between the financial and productive spheres, the post-Keynesians justify the need to promote monetary and financial regulation. In the analysis, we see clearly that monetary policy should not be dedicated exclusively to combating inflation, as well as the fact that the State's great non-interventionism does not exempt the overall system from risks to its stability.

Key words: endogenous money, banking system, interest rate, post-keynesian monetary theories.

* Maître de conferencia, Université de Bourgogne. Correo electrónico: Pierre.Piegay@U bourgogne.fr

** Profesor agregado, Departamento de Economía, Université Laurentienne, Canadá. Correo electrónico: 1prochon2003@yahoo.com 
Résumé

Ce texte est une présentation synthétique des caractéristiques essentielles des théories monétaires post keynesiennes. Nous désirons montrer que, dans le cadre institutionnel actuel, ces caractéristiques constituent un outil pour appréhender le fonctionnement de nos économies monétaires. Lorsqu'on dérègle les relations entre les sphères financière et productive, les post keynésiens justifient le besoin de promouvoir une régulation monétaire et financière. Dans l'analyse on peut voir clairement que la politique monétaire ne doit pas être exclusivement dédiée à la lutte contre l'inflation, car en plus le grand désintérêt de l'Etat n'exempte pas de risques la stabilité du système dans sa totalité.

Mots-cléfs: monnaie endogène, système bancaire, taux d'intérêt, théories monétaires post keynesiennes.

\section{Resumo}

Este texto é uma apresentação sintética das carateristicas esenciais das teorias monetárias poskeynesianas. Desejamos mostrar que, no marco institucional atual, tais teorias constituiem uma ferramenta útil para apreender o funcionamento de nossas economias monetárias. Ao descompor as relações entre as esferas financeira e produtiva, os poskeyesianos justificam a necessidade de promover a regulação monetária e financeira. Na análise pode se ver claramente que a política monetária não deve estar exclusivamente dedicada à luta contra a inflação, além do que o grande desentendimento do Estado não exime de riscos na sua totalidade à estabilidade do sistema.

Palavras chave: moeda endogênia, sistema bancário, taxa de interesse, teorias monetárias pós-keynesianas. 


\section{Introducción}

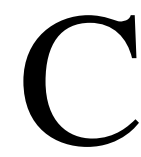

omo lo recuerda Dostaler, "es necesario desconfiar de los que pretenden detentar la exclusividad - y, por supuesto, la tenencia de la verdad- sobre teorías, paradigmas, sistemas, sean cuales fueren. Es necesario desconfiar, sobre todo, de los que pretenden poseer el verdadero sentido, derivado de una hipótesis única, de Marx o de Keynes. Existen tal vez varios sentidos tanto en uno como en el otro" (1988:138). Parece legítimo, entonces, pensar que ningún enfoque puede jactarse del monopolio de la verdad. Con respecto de la obra de Keynes, esta advertencia resulta tanto más convincente en tanto las interpretaciones son diversas. La complejidad del sistema económico actual nos invita a ser prudentes cuando se trata de sugerir un análisis. Aquí no pretendemos afirmar que el programa de investigación poskeynesiano posee la verdad acerca del verdadero mensaje de Keynes. Para ello, convendría aceptar un desafío imposible: definir cuál sería ese verdadero mensaje.

En este texto la intención es más modesta: mostrar que las teorías monetarias poskeynesianas son fieles a ciertos aspectos del análisis de Keynes y cuáles de ellos constituyen importantes avances. De ese modo, la teoría poskeynesiana puede considerarse un regreso a Keynes y una prolongación de algunas de sus intuiciones más innovadoras (King, 2002). ${ }^{1}$ Al buscar sistematizar ciertos aspectos no definidos en su análisis, el enfoque poskeynesiano se distingue de los más ortodoxos. Conocemos el deseo de Keynes de elaborar una teoría económica nueva y alternativa. En su proyecto inicial existía una ambición radical acompañada de la convicción de estar creando los fundamentos de una verdadera "revolución". ${ }^{2}$ Así, se ubica del lado de los "herejes" y pretende desafiar a las "fuerzas de la ortodoxia" (1973a:488).

En esa perspectiva, la crítica a la teoría neoclásica es un punto de convergencia de los poskeynesianos. Sin embargo, no creemos que por ello haya que delimitar la unión -y menos aun el aporte- de éstos a esa única dimensión crítica; por el contrario, querríamos subrayar aquí que hacen una contribución positiva y sustancial a la teoría monetaria en el

Lavoie (2004a) expone sus principales características.

2 Antes de la aparición de Teoría general, en una carta del primero de enero de 1935, Keynes expresa a George Bernard Shaw su sensación acerca del trabajo que está realizando: "Creo estar redactando un libro de teoría económica que revolucionará -imagino que no inmediatamente pero a lo largo de los próximos diez años - la manera en la que el mundo enfoca los problemas económicos", y aclara lo siguiente: "No puedo pedir ni a usted ni a nadie que lo crea por el momento. Pero en lo que me concierne no me conformo con esperarlo, estoy profundamente persuadido" (Keynes, 1973a:492 493).

\section{DeSarrollo}


marco institucional actual. En este trabajo no podemos dar una visión de conjunto de las teorías monetarias poskeynesianas (Piégay y Rochon, 2003), pues el objetivo es presentar brevemente los principales argumentos teóricos y las recomendaciones de política que de ellos se desprenden. Sus principales características se presentan en cuatro etapas. En primer lugar, estudiamos la relación entre macroeconomía, moneda y producción. Enseguida analizamos el papel del sistema bancario en la creación de moneda endógena y la formación de la tasa de interés. Asimismo, presentamos el lugar que ocupa la moneda en la explicación de la disfunción de nuestro sistema económico. Finalmente, discutimos brevemente las diferencias entre la teoría poskeynesiana y la del circuito monetario. Aunque no podemos hacer justicia aquí a esos debates (véase, por ejemplo, Rochon, 1999), abordaremos algunas de las similitudes y diferencias entre éstos.

\section{Macroeconomía, moneda y producción}

El punto de partida analítico de los poskeynesianos evidentemente es Keynes, lo cual no quiere decir que debamos seguir sus enseñanzas al pie de la letra. Por ello, previamente a la construcción de un análisis coherente y compatible con las instituciones actuales, es necesario identificar los límites de su análisis, elaborado hace setenta años. Su obra provee las bases de un enfoque moderno de la teoría monetaria y de sus implicaciones en términos de política económica. Los poskeynesianos buscan superar esas limitaciones al desarrollar los elementos más radicales y descartar los más conservadores (Cottrell, 1994:588). Éste es el caso, por ejemplo, de la hipótesis de la oferta monetaria exógena, adoptada por Keynes en Teoría general y excluida en favor de la oferta monetaria endógena dentro de la lógica del principio de la demanda efectiva.

Al respecto, la Teoría general no es el único material a disposición de los poskeynesianos. De hecho, ésta no es "la última palabra teórica" de Keynes en materia monetaria (Arena, 1984): a los ojos de aquellos aparece como el esqueleto de un proyecto más ambicioso. El corpus común de su análisis es más amplio: sobre todo se encuentra constituido de esbozos de la Teoría general y de artículos inmediatamente posteriores a su publicación, así como de algunos elementos innovadores contenidos en el Tratado de la moneda. Los trabajos de Kalecki y de Sraffa son también fuente de inspiración fecunda. ${ }^{3}$ No obstante, es necesario destacar que los poskeynesianos no son precursores en lo que respecta al rechazo del enfoque cuantitativista, al análisis del papel de los bancos y de la oferta monetaria endógena. Los tenedores del banking principle enunciaban ideas análogas desde el siglo XIX (Diatkine, 1995:31 y ss).

3 Por ejemplo, Lavoie (1992) muestra la convergencia de sus análisis. Con respecto del aporte específico de Kalecki véanse Dostaler (1988) y Sawyer (2003).

\section{DeSarrollo}


Por medio de su Teoría general, Keynes quería establecer un análisis de las economías monetarias de producción, en las cuales los empresarios expresaran una demanda de créditos a los bancos con fines productivos. Los factores de la producción son remunerados directamente mediante la moneda y la producción debe obtener beneficios monetarios. El énfasis puesto en la moneda (como componente esencial del sistema económico) distingue claramente su enfoque del modelo neoclásico. No integrarla al análisis de la determinación del empleo y del nivel de producción no puede más que generar consecuencias "engañosas y nefastas" (Keynes, 1936:33).

Desde esta perspectiva, uno de los principios centrales de las teorías monetarias poskeynesianas es considerar a la moneda como flujo endógeno necesario para la puesta en marcha de la producción (un análisis en términos de composición de cartera no puede constituir un buen punto de partida). ${ }^{4}$ En efecto, de antemano, poner el acento en la preferencia por la liquidez implica ver la moneda como un stock que asignar de la mejor manera posible. Si ésta es una variable exógena y los bancos son considerados esencialmente intermediarios financieros, se torna delicado "explicar la particularidad de la moneda y específicamente en qué se distingue ésta de las finanzas" (Deleplace y Nell, 1996:33). Sin embargo, como lo plantean estos dos autores, se trata de una "pieza necesaria para toda teoría monetaria" (ibid.). La preferencia por la liquidez se encuentra integrada, entonces, al análisis cuando nos interesamos en las razones por las cuales los agentes detienen una cartera y en qué manera la constituyen (infra:18-19).

Para los poskeynesianos, la perspectiva trazada por los enfoques de composición de cartera no es satisfactoria dado que, como lo indican Kaldor y Trevithick, si la distinción entre la moneda y otros activos financieros recae en el grado de liquidez, " es imposible dar una definición de moneda carente de ambigüedad [...] No existe una distinción clara entre 'moneda' y 'no moneda', ni principio claro que sirva de guía para hallar la definición ideal de moneda" (1981:12).

En Teoría general, Keynes rechaza separar la teoría monetaria del resto del análisis. Desde esta visión, los enfoques dicotómicos son necesariamente pistas falsas, dado que no es posible aprehender los fenómenos económicos fundamentales en términos reales, independientemente de los monetarios. Dicho de otra manera, es ilusorio intentar analizar el funcionamiento efectivo de nuestras economías sin recurrir, desde el inicio, a la moneda. La comprensión de los mecanismos económicos esenciales requiere de ésta desde el punto de partida de su análisis; no se le debe introducir a posteriori para así dar cuenta de su existencia, como si ello no cambiara fundamentalmente nada. Los poskeynesianos se niegan a creer en la "fábula del trueque", la cual pretende explicar la integración de la

4 Nos alejamos de la línea iniciada a partir de trabajos de Tobin (1956 y 1971), Markowitz (1959) y Baumol (1971).

\section{DeSarrollo}


moneda en la economía. ${ }^{5}$ Las esferas reales y monetarias se encuentran íntimamente ligadas, dado que la moneda se vincula a la economía en la producción por medio de los bancos.

Según Keynes, la correcta dicotomía no es entre lo real y lo monetario, sino entre la micro y la macroeconomía: "la división correcta, de acuerdo a nuestro criterio, establece por un lado la teoría de la firma o de la industria individuales así como las remuneraciones y la distribución entre sus diferentes usos de una cantidad dada de recursos y, por el otro lado, la teoría de la producción y del empleo en su conjunto" (Keynes, 1936:297). A diferencia de la microeconomía, la cual intenta explicar la asignación óptima de una selección de bienes y servicios dados, la especificidad de la macroeconomía radica en brindar una explicación de la formación de los agregados y, sobre todo, del ingreso. Siguiendo los lineamientos de Keynes acerca de este punto, los poskeynesianos, contrariamente a los nuevos keynesianos, no priorizan la búsqueda de los fundamentos microeconómicos de la macroeconomía. Estos últimos han fundado el éxito de sus trabajos en una severa exposición de las rigideces microeconómicas y de las disfunciones que de ellas se derivan. De ese modo, han podido responder a las críticas de los nuevos clásicos acerca de la falta de fundamentos micro de la macroeconomía keynesiana (Arena y Torre, 1992). Por el contrario, los poskeynesianos adoptan un enfoque esencialmente macroeconómico: el análisis de los comportamientos individuales no les resulta un punto de partida obligatorio. ${ }^{6}$ A su vez, consideran que existen "leyes puramente macroeconómicas [...] independendientes de los comportamientos de los agentes microeconómicos” (Lavoie, 1987a:73).

Keynes recuerda, entre otras cosas, que "desde el momento en que buscamos los determinantes de los volúmenes globales de la producción y del empleo, la teoría completa de una economía monetaria se torna indispensable" (Keynes, 1936:297). La moneda está introducida desde el comienzo, dadas las necesidades del análisis. El principio de la demanda efectiva representa el concepto clave de una iniciativa de ese tipo, pues constituye la explicación del establecimiento de los niveles de producción y de empleo en unidades monetarias. La problemática planteada en términos de unidades salariales monetarias es significativa en este punto. En efecto, según Diatkine, "Keynes se niega a recurrir a medir la producción global a través de un sistema de precios relativos [...] La unidad de medida propuesta por Keynes es la del salario monetario. De hecho, la moneda está postulada desde el comienzo en el análisis, ésta constituye el objeto prioritario de estudio e instrumento de sociabilización" (1988:145).

Acerca de estos temas cruciales podemos remitir al número especial de Économie Appliquée, Économie réelle-Économie monétaire, coordinado por Barrère (1985).

6 Cencini (2003) y Graziani (2003). Las distinciones entre pos y nuevos keynesianos son abordadas en Rotheim (1998), Rochon (1999) y Piégay (2000).

\section{DeSarrollo}


El análisis de la producción es un elemento central, dado que es la operación económica mediante la cual los ingresos monetarios se crean y por medio de la cual la moneda se integra a la economía. Se trata de explicar la creación de ingresos, pues no se analiza la producción como simple relación de intercambio. La relación salarial es específica pues provee el marco de análisis de la formación de los ingresos (particularmente Schmitt, 1960, 1966 y 1984). Acerca de este punto específico, los poskeynesianos se han beneficiado de las contribuciones de los circuitistas, los cuales concentran justamente ahí sus esfuerzos. $^{7}$

Estos últimos estudian el funcionamiento del sistema económico mediante los flujos monetarios que ligan los diferentes polos funcionales, constituidos por bancos, empresas, hogares o el Estado (Gnos, 2003; Parguez y Seccareccia, 2000). De acuerdo con esa perspectiva, los enfoques dicotómicos son banales, debido a que las actividades productivas de las empresas dan origen a los ingresos monetarios que permiten la realización de los bienes y servicios disponibles. De este modo, la producción es la operación primaria y se establece que "la moneda es tan significativa como los bienes. Esto último indica que ésta no se limita a reflejar los hechos que se producen en la esfera de lo real sino que, de acuerdo a la expresión de François Perroux, 'ésta los incita'" (Barrère, 1990:5).

En la medida en que la moneda se encuentra integrada a la economía por medio del sistema bancario, el cual financia la producción, éste juega un papel determinante, ya que realiza las emisiones monetarias y permite, gracias a su actividad crediticia, asegurar el financiamiento de la actividad.

\section{Oferta monetaria, tasa de interés y sistema bancario}

Del análisis del papel del sistema bancario en la creación monetaria y en la formación de la tasa de interés se desprenden dos características esenciales del análisis poskeynesiano. La primera es que la determinación de la tasa de interés no surge de un proceso de mercado; se trata de una variable exógena fijada por el banco central en función de sus objetivos de política monetaria. La segunda es que la oferta es endógena y determinada por el sistema bancario en respuesta a las necesidades de la economía de producción.

La tasa de interés, como variable exógena, es un concepto clave para los poskeynesianos. Luego de Keynes, ${ }^{8}$ numerosos autores han considerado que el banco central puede fijarla

7 Para una presentación de las teorías del circuito keynesiano, Lavoie (1987a) y Graziani (1990).

8 Véase, por ejemplo, el argumento decisivo adelantado por Keynes en marzo de 1945: "las autoridades monetarias pueden elegir la tasa de interés que ellas desean [...] Ellas pueden fijar a la vez [la tasa] de corto y de largo plazo de acuerdo a su conveniencia, o más bien en el nivel que les parezca adecuado [...] Históricamente, las autoridades siempre han determinado la tasa según su buena voluntad y han sido influenciadas casi exclusivamente por objetivos de balanza comercial" (1945/ 1980:390 392].

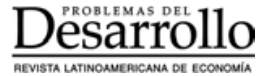


en el nivel que más le convenga, teniendo en cuenta sus objetivos de política. Robinson abrió el camino desde 1956, pero ciertamente es Kaldor (1970) uno de los principales defensores de esta tesis. Sus trabajos han dado nacimiento a lo que llamamos la corriente horizontalista (Kaldor, 1985; Lavoie, 1992; Moore, 1988; Rochon, 1999 y Seccareccia, 1996).

Para estos autores, no se puede hablar de mercado monetario, lo cual los aleja de la posición de Keynes en Teoría general. A este efecto, Rochon (1997) muestra que inmediatamente después de la publicación de esa obra, Keynes adoptó la moneda endógena y la determinación de una tasa de interés exógena. Desde esta perspectiva, no es la interacción entre la oferta y la demanda monetaria la que determina la tasa de interés para un stock de moneda dado. De hecho, los poskeynesianos rechazan la noción de control de la oferta por la autoridad monetaria.

Podemos hallar ese tipo de argumento en el seno de la nueva economía keynesiana (McCallum, 2001; Meyer, 2001). En ese sentido, Bradford Delong afirmó que la curva LM debería ser descartada dado que la hipótesis según la cual "el banco central fija el stock monetario es simplemente falsa" (Delong, 2001:1). Ello se encuentra igualmente implícito en la formulación de la regla de Taylor. Sin embargo, contrario a los nuevos keynesianos, los poskeynesianos rechazan el concepto tasa de interés natural, tomado de Wicksell y no adoptan esa regla de conducta de la política monetaria (Smithin, 2004). ${ }^{9}$ Siendo para ellos la tasa de interés un objetivo intermediario, el fin es una distribución del ingreso destinada a conducir al pleno empleo y no a la lucha contra la inflación. Los poskeynesianos no creen que una única tasa de interés (la tasa natural) sea compatible con una situación de pleno empleo. Si adoptamos una política fiscal destinada a corregir la desigualdad de ingresos, el pleno empleo puede ser alcanzado con distintos niveles de tasa de interés.

En ese sentido, la tasa de interés debería ser fijada para asegurar transferencias de riqueza desde los individuos con mayor propensión a ahorrar hacia los de mayor propensión a consumir. Al respecto, Keynes pregonaba una política de baja de las tasas de interés y "la eutanasia de los rentistas". De acuerdo con Smithin (2003), las políticas de alza de tasas de interés deben ser consideradas como una "revancha de los rentistas". Según los poskeynesianos, la tasa de interés es una variable redistributiva (Rogers, 1989; Lavoie, 1992; Smithin, 2003), dado que las tasas elevadas penalizan tanto a las empresas en el desarrollo de sus actividades, como a los asalariados por el incremento en el desempleo, pero benefician a los que obtienen ingresos de los intereses de sus riquezas. ${ }^{10}$ Lavoie (2005a) destaca que la obsesión por la lucha contra la inflación lleva ineludiblemente a una política de alza de dichas tasas.

9 Para una crítica de este enfoque véanse, por ejemplo, Lavoie (2004b y 2005a) y Rochon (2004).

10 Los asalariados, obviamente, pueden detentar activos financieros que rinden interés.

\section{DeSarrollo}


Las variaciones de ésta modifican tanto la distribución del ingreso como la demanda global que, a su vez, influye en la evolución de la actividad. En consecuencia, los poskeynesianos consideran que los bancos centrales deberían estar más preocupados por la distribución del ingreso como motor del crecimiento económico que por un objetivo de lucha contra la inflación. ${ }^{11}$

Por otra parte, el alza de las tasas de interés no reduce necesariamente las presiones inflacionistas: los poskeynesianos aportan una respuesta a la paradoja de Gibson al explicar cómo el alza de las tasas de interés puede acompañarse de un aumento de precios. Dado que estos precios se fijan sobre la base de un margen aplicado a los costos de producción, el incremento de las cargas financieras mediante el aumento de la tasa de interés se traslada a los precios por las empresas. Llevar a cabo una política de alza de dichas tasas eventualmente podría limitar las presiones inflacionarias al costo de una reducción de la demanda global, que sumergiría a la economía en una recesión.

El concepto oferta monetaria endógena constituye el segundo pilar del enfoque poskeynesiano y es objeto de amplio consenso. Más que postular una oferta monetaria exógena con el control del banco central, considera que la moneda es creada por los bancos comerciales en respuesta a las demandas de crédito; según la perspectiva del divisor de crédito, éste genera los depósitos y éstos, a su vez, reservas (Lavoie, 2003:525; Le Bourva, 1959). Esta concepción plantea dos cuestiones: el papel del banco central y la implicación de los bancos comerciales en el proceso de creación monetaria.

En respuesta a la primera cuestión, los poskeynesianos afirman que el banco central alimenta el sistema con liquidez. Además de determinar la tasa de interés, éste asegura el buen funcionamiento del sistema financiero. Rochon y Rossi (2004) desarrollaron un análisis del papel del banco central en el marco de las evoluciones institucionales recientes. La organización de la compensación permite al banco central asegurar el cumplimiento de los pagos y limitar el riesgo sistémico. Dado que las transacciones dan lugar a transferencias interbancarias, es necesario asegurarse que los bancos dispongan de la liquidez suficiente para poder honrar sus compromisos. La falta de ésta podría, en efecto, poner a determinados establecimientos en una posición delicada, susceptible de propagarse al conjunto del sistema. Regulándola en los bancos, la institución central se asegura de que haya la necesaria. En caso contrario, dicho sistema se encuentra listo para proveerla a los bancos deudores. Los procedimientos de refinanciación automáticos corresponden a este modo defensivo de intervención de los bancos centrales, pues de ese modo actúa cotidianamente en los mercados para asegurar su correcto funcionamiento. En su papel de prestamista de última instancia, éstos deben mantener la estabilidad y la perduración del sistema de pagos.

11 Además, es necesario destacar que la lucha contra la inflación beneficia prioritariamente a los acreedores. 
De este análisis se concluye que los bancos centrales no pueden controlar la oferta monetaria. La disminución (incluso la supresión) generalizada de las reservas obligatorias y la presencia de procedimientos de refinanciamiento automático son una ilustración de ello. La tasa de interés constituye un instrumento privilegiado de los bancos centrales, tanto en los sistemas basados en los créditos como en los títulos financieros (Lavoie, 2005b). De acuerdo con el punto de vista horizontalista, la curva de oferta monetaria es horizontal dado que la oferta monetaria está determinada de manera endógena por la tasa de interés fijada por el banco central. Este punto fue objeto de numerosos debates en el seno de la escuela poskeynesiana, con la controversia entre los horizontalistas y los estructuralistas, partidarios de una curva de oferta monetaria ascendente (Piégay, 2001; Rochon, 1999). No obstante, según Moore, este debate resultó ser una "tormenta en un vaso de agua" (2001:14) y no parece continuarse en la actualidad.

La segunda cuestión concierne al papel de los bancos en la creación monetaria. Según los poskeynesianos, la integración de la moneda se efectúa por medio de los préstamos de los bancos comerciales. Estos últimos no están únicamente acotados para ser simples intermediaros financieros; las firmas obtienen de ellos los fondos necesarios en el corto plazo, en forma de líneas de crédito, por ejemplo, y obtienen préstamos en el largo plazo para el financiamiento de la inversión. Los bancos solamente pueden prestar a quienes lo demandan, por lo cual su oferta de préstamos está determinada por la demanda. En consecuencia, no podemos considerar que las reservas constituyan condición previa y necesaria para la creación monetaria: aunque los bancos dispusieran de un excedente de reservas, no podrían acordar créditos sin una demanda expresa de los prestatarios.

De hecho, los poskeynesianos consideran que los bancos otorgan los fondos demandados a los prestatarios solventes y ello da origen a depósitos reflejos. En ese sentido, Moore afirma que la creación monetaria está determinada por la demanda y, a su vez, guiada por el crédito. Los bancos registran las operaciones y realizan los pagos a cuenta de sus clientes. Dichos pagos provocan movimientos desde las cuentas de los bancos hacia el central, de acuerdo con la jerarquía del sistema. El papel de aquéllos es, entonces, esencial, dado que su actividad permite, al mismo tiempo, la creación monetaria y el financiamiento del crecimiento.

A fin de evaluar la solvencia de los prestatarios, los bancos hacen uso de determinados criterios, los cuales se encuentran mayoritariamente en control del prestatario. Éstos analizan los balances de las firmas, evalúan las garantías y los flujos descontados de fondos. Su principal preocupación es determinar si el prestatario será capaz de generar fondos suficientes para enfrentar los costos del préstamo.

Según Wolfson, "la hipótesis poskeynesiana más apropiada es que tanto el prestamista, como el prestatario se encuentran sujetos a una incertidumbre fundamental sobre el futuro" (1996:450). En este marco, la capacidad del prestatario de reembolsar su deuda puede

\section{DeSarrollo}


verse modificada por la evolución de las tasas de interés y de la demanda global; estos dos elementos afectan la situación financiera del prestatario mediante el costo de su deuda (especialmente si debe ser renovada en el corto plazo) y de sus ingresos. En el caso de una evolución desfavorable, el prestatario puede tornarse insolvente a los ojos de los bancos, los cuales se negarán a prestarle. De este modo, aunque la oferta de crédito esté determinada por la demanda, depende igualmente de la solvencia del prestatario y del nivel de las garantías. Entonces, los bancos tienen la capacidad de determinar a quién prestan; como lo destaca Wolfson: "los banqueros ordenan las demandas solventes de créditos y racionan las que juzgan insolventes" (ibid::455).

Estos elementos pueden, a su vez, estar influidos por la política monetaria y fiscal. La monetaria tiene un papel central, dado que, al mantener tasas de interés bajas, el banco central puede sostener la demanda global y la solvencia de los prestatarios. La política fiscal es de igual modo determinante, ya que puede alimentar la demanda y evitar la degradación de la solvencia de los prestatarios. Como lo hemos visto, dicha solución puede tener un impacto en la distribución del ingreso con el objeto de estimular el consumo. El gasto público constituye una salida para las empresas que venden directamente al Estado o que se benefician de los ingresos de transferencias. Las políticas coyunturales deben hacer lo necesario para sostener el otorgamiento de créditos y, más aun, la actividad en su totalidad.

\section{Incertidumbre, moneda y crisis}

Si bien los argumentos presentados son ampliamente compartidos por los poskeynesianos, algunos de ellos ponen particular acento en la incertidumbre del entorno económico: dicho énfasis en la incertidumbre radical es una de las características fundamentales de la teoría monetaria poskeynesiana. ${ }^{12}$ Esta noción, ya presentada en el Tratado de las probabilidades, la retoma Keynes en el capítulo 12 de Teoría general. En su artículo de 1937, expone claramente su punto de vista: "Me es necesario explicar que, a través de la expresión 'incierta', mi intención no es simplemente distinguir lo que es sabido de lo que sólo es probable [...] Utilizo el término en el sentido en que [...] no hay fundamento científico en el cual podamos formular la cuestión de probabilidad" (1937/1973b:113114). También concluye que, respecto de la aparición y el alcance de ciertos hechos futuros, lo único que podemos decir es que "simplemente, no lo sabemos" (ibid.).

Si el entorno económico está sumergido en esa incertidumbre radical, entonces "el objetivo de la teoría [poskeynesiana] es tornar inteligible el mundo real, y no reemplazarlo por un mundo ideal" (Davidson, 1986:260). En ese contexto, cuando los agentes económicos

12 En este área, los trabajos de Davidson (1972, 1983 y 2003) son referentes esenciales.

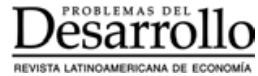


toman las decisiones comprometen el futuro, sin que los resultados puedan ser descontados con certidumbre. El porvenir no es perfectamente previsible dado que "el futuro es creado por las decisiones cruciales" (Davidson, 1983:192). ${ }^{13}$ De ese modo, el análisis es llevado al marco de un tiempo "histórico" (Dostaler, 1988 y Davidson, 1983), es decir, a una situación en la cual las decisiones son irreversibles e influyen directamente en el escenario futuro. En esta línea, no podemos apelar a un hipotético secretario de mercado para organizar la coordinación de las decisiones; toda posibilidad de renegociación se encuentra, entonces, descartada.

Sin embargo, esta característica del contexto no conduce a la ausencia de decisiones y a la inacción. Keynes establece las bases del análisis del proceso con los famosos "espíritus animales":

las decisiones humanas comprometedoras del futuro en el plano personal, político o económico no pueden inspirarse en una estricta previsión matemática, dado que la base de tal previsión no existe [...] nuestra necesidad innata de actividad constituye el verdadero motor de los negocios, nuestra mente eligiendo lo mejor posible entre las soluciones viables, calculando cada vez que puede, pero apartándose muy a menudo ante los impulsos de los caprichos, al sentimiento o a la suerte (1936:100).

En un contexto de este tipo, las acciones empresarias se apoyan en decisiones subjetivas en las cuales la fiabilidad puede ser frágil. De este modo, comprendemos que los agentes busquen mejorar su actuación, al volcarse hacia la opinión común y adoptar un comportamiento mimético (por ejemplo, Keynes, 1937/1973b:114, y 1936, cap. 12). Al ubicarse de antemano en un marco de tiempo histórico y de un futuro no probabilístico, el análisis poskeynesiano se aproxima al conjunto de trabajos acerca de las convenciones y el mimetismo estratégico. ${ }^{14}$ "En este, nuestro mundo, los agentes económicos se enfrentan continuamente a la incertidumbre. A fin de hacer frente a lo desconocido de manera racional, los agentes se fijan normas, reglas de conducta, hábitos, convenciones" (Lavoie, 1987b:125).

Sin minimizar la importancia de los bancos en la creación monetaria, el recurso a la incertidumbre radical constituye para ciertos poskeynesianos un medio complementario para justificar la integración de la moneda en la economía de acuerdo con dos ejes.

En su calidad de unidad de cuenta, la moneda interviene, en primer lugar, en el establecimiento de contratos. Esta dimensión es primordial, dado que es la unidad de cuenta en la cual se expresan las relaciones monetarias y se realizan pagos. "La moneda de cuenta, es decir, eso en lo cual las deudas, los precios y el poder adquisitivo están generalmente expresados, es el concepto principal de una teoría de la moneda" (Keynes, 1930/1971:3).

El concepto de decisiones cruciales ha sido desarrollado por Shackle (1955).

14 Sobre este punto, Dupuy et al. (1989) y Orléan (1994). Acerca de los aportes de Keynes, Favereau (1988).

\section{DeSarrollo}


Acorde con esta perspectiva, Davidson muestra que la economía es monetaria, pues las relaciones entre individuos se hacen en forma de contratos estipulados en moneda (Davidson, 1972: cap. 6). Éste es, sobre todo, el caso de los contratoslaborales en el marco de una producción cuyo resultado es incierto; éstos se encuentran en el origen de la integración de la moneda a la economía y, en consecuencia, de su utilización en otras formas de contrato. ${ }^{15}$

Por otro lado, como reserva de valor, la moneda permite prevenirse de los vaivenes de un mundo incierto. ${ }^{16}$ Nos acercamos aquí al análisis de la preferencia por la liquidez. Keynes justifica la tenencia de moneda de la siguiente manera:

[la moneda] es una reserva de valor [...] Pero en el mundo de la economía clásica, qué uso insensato es atribuírselo dado que reconocemos que la moneda como reserva de valor tiene la característica de ser estéril; mientras que en la práctica todas las otras formas de conservación de la riqueza otorgan un interés o un beneficio. ¿En virtud de qué, alguien — salvo en un asilo de locos — podría querer utilizar la moneda como reserva de valor? Por motivos en parte racionales o instintivos, nuestro deseo de tenencia de moneda como reserva de valor es un barómetro de nuestro grado de desconfianza hacia nuestros propios cálculos y convenciones respecto al futuro [...] La posesión de moneda calma nuestra inquietud, y la prima que requerimos para incitarnos a separarnos de la moneda es la medida del grado de nuestra inquietud (1937/1973b:115-116).

Poner énfasis en el hecho de que los contratos están estipulados en moneda revela el funcionamiento de las economías monetarias de producción. Dado que los salarios son pagados con ésta, los empresarios deben pedirla prestada a los bancos, por ello los contratos entre las firmas y los éstos son expresados en moneda. Los bancos crean la moneda en las operaciones de crédito. Los ingresos son, a continuación, en parte consumidos, en parte conservados, para hacer frente a un futuro incierto. La relación expuesta por Davidson entre incertidumbre y moneda aparece así en diferentes etapas del circuito. Según el punto de vista de Davidson, "las instituciones que establecen los puentes entre el presente y el futuro crean las condiciones para que los agentes económicos acepten la tenencia de moneda" (Rochon y Vernengo, 2003:186-187).

15 En ese sentido, véase el argumento de Weintraub (1982:364): "Tenemos un sistema de precios monetarios porque tenemos un sistema de salarios monetarios y no a la inversa". Es necesario destacar que para los teóricos del circuito monetario la incertidumbre no es necesaria para explicar la existencia de la moneda. Es, principalmente, el análisis de la naturaleza específica del proceso de producción la que provee la explicación. Claramente, la consideración de la incertidumbre en el análisis establece una relación interesante entre estas dos corrientes. Acerca de este punto, Fontana (2000).

16 Las dimensiones de unidad de cuenta, de medio de pago y de reserva de valor están íntimamente ligadas, ya que "la moneda en sí misma, es decir, lo que libera de los contratos de deuda o de los contratos de precios y la forma en la cual el poder adquisitivo general es detenido, extrae su naturaleza de la relación con la moneda de cuenta dado que las deudas y los precios deben, en un comienzo, ser expresados en términos de esta última" (Keynes, 1930/1971:3).

\section{DeSarrollo}


Aquí se pone el énfasis en la moneda porque, en tanto "liquidez por excelencia", provee las bases para una explicación de la crisis de las economías monetarias de producción. Keynes insiste en su no neutralidad, es decir, que ésta interviene en el corazón del análisis de la disfunción de nuestras economías.

En el capítulo 17 de Teoría general, Keynes da una explicación estructural del desempleo fundada en las características específicas de la moneda (Bradley, Piégay y Rossi, 2003). Una demanda excesiva puede trabar el desarrollo de la inversión productiva dado que las propiedades esenciales de la moneda son tales que no es posible disuadir su demanda. El nivel excesivo de la tasa de interés monetaria contraría las posibilidades de expansión de los planes de inversión de los empresarios. El nivel de la demanda global resulta, entonces, insuficiente para permitir el retorno al pleno empleo.

Para los teóricos del circuito monetario, la moneda se halla también en el origen de la disfunción de las economías empresariales. ${ }^{17}$ Éstos consideran que la preferencia por la liquidez conduce a la interrupción del flujo de renta hacia las empresas y a una demanda global insuficiente. Si parte del ingreso creado se conserva en forma de fondos líquidos, los empresarios no podrán recuperar mediante las ventas la totalidad de los montos invertidos en la producción. Siguiendo el principio de la demanda efectiva, esto deprime las previsiones de beneficios de los empresarios, penaliza el desarrollo de la producción y, por ende, la mejora en la situación del empleo.

El análisis de la moneda endógena y de las estructuras "financieras sofisticadas" actuales brinda, a su vez, la posibilidad de sugerir una explicación de la inestabilidad de nuestras economías. Keynes, en su presentación de los principales lineamientos de su teoría monetaria de la producción, afirma que "los booms y las depresiones son fenómenos específicos de una economía en la cual [...] la moneda no es neutral” (Keynes, 1933/ 1973a:411). Esta pista de investigación es particularmente explorada por Minsky (1986), siguiendo las huellas de Fisher (1933).

Fisher propone una explicación a la crisis de 1929, fundada en el sobreendeudamiento y en la deflación. Las perspectivas de beneficio dadas por la innovación provocan un alza de la inversión, que necesita de un endeudamiento creciente. Si la situación se prolonga hasta alcanzar un sobreendeudamiento, la necesaria depuración de las deudas, provocada por la reversión de la coyuntura, puede conducir a una caída de precios. Dado que la

17 Por ejemplo, Parguez y Seccareccia (2000) y Rochon (1999). Al respecto, es necesario destacar la diferencia con la teoría monetaria de Schmitt, para quien su naturaleza - a la cual distingue de los activos financieros - no nos autoriza a ubicarla en el origen de la patología de las economías monetarias de producción. Los males de los cuales estas últimas son víctimas se originan en el proceso de acumulación del capital y en la organización actual del sistema bancario (Schmitt, 1984; Baranzini y Cencini, 1996).

\section{DeSarrollo}


deflación incrementa el poder adquisitivo de las deudas, es posible que los esfuerzos destinados a reducir el endeudamiento conduzcan a su incremento.

La deflación provocada por la deuda repercute sobre la deuda [...] Si el sobreendeudamiento del que partimos fuera suficientemente elevado, la liquidación de las deudas no podría seguir el ritmo de la caída de precios que acarrea. En este caso, la liquidación es la causa de su propio fracaso [...] De este modo, el esfuerzo de los individuos para disminuir el fardo de las deudas lo aumenta [...] cuanto más se reembolsan las deudas, más se debe" (Fisher, 1933/ 1988:173).

Con base en esto se desencadena una espiral deflacionaria que deprime la actividad; las quiebras de los deudores conducen a la de los acreedores, dando lugar al derrumbe del sistema en su totalidad.

En esta perspectiva, Minsky propone un análisis de la inestabilidad financiera ligado a la degradación natural de la estructura financiera. Su hipótesis siembra las bases de un análisis endógeno de las fluctuaciones macroeconómicas (Nasica, 1997; Brossard, 1998). Esta dinámica endógena está fundada en el endeudamiento creciente, el cual puede acompañar al desarrollo de la actividad. Si bien este endeudamiento permite incrementar la rentabilidad de los proyectos emprendidos, también se encuentra en el origen de la degradación de la estructura financiera de los agentes. Desde una situación financiera sana, en la cual la expansión prospera, podemos movernos hacia una situación cada vez más frágil e inestable, caracterizada por un incremento de la proporción de agentes con estrategias especulativas y Ponzi. 18 "El riesgo de aparición de una crisis financiera aumenta porque la probabilidad de que el alza de las tasas de interés induzca la reversión de los valores actualizados es cada vez mayor cuanto más elevado es el peso del financiamiento especulativo y Ponzi" (Minsky, 1982, citado por Nasica, 1997:858). En otros términos, una situación financiera estable puede generar inestabilidad. Los trabajos en la línea del de Minsky dotan a la teoría poskeynesiana de un análisis de la dinámica de las economías monetarias. Éstos nos muestran que el funcionamiento natural de nuestro sistema puede acompañarse de inestabilidad creciente, la cual forma parte del origen de las crisis que marcan su desarrollo.

Desde esta perspectiva, los poskeynesianos apelan a la intervención del Estado para prevenir las crisis y frenar, en su defecto, el contagio. Perpetuando la herencia de Keynes en cuanto a la necesidad de políticas coyunturales, los poskeynesianos justifican la puesta en marcha de políticas monetarias y presupuestarias. Los gastos presupuestarios del Estado se consideran estabilizadores automáticos y contracíclicos, capaces de oponerse a los fenómenos de propagación y limitar el riesgo sistémico. La intervención del prestamista de última instancia y su papel esencial en la regulación del sistema bancario forman parte de la

18 Para estos últimos, los ingresos son insuficientes para enfrentar las costos de los préstamos, intereses y capital. Ven entonces sus deudas incrementarse en cada periodo (Brossard, 1998:418).

\section{Desaarrollo}


misma lógica. La política monetaria de regulación de las tasas de interés establece claramente un objetivo de sostén de la actividad económica.

Globalmente, el capitalismo con un Estado influyente y un Banco Central intervencionista, capitalismo en vigor desde la Segunda Guerra Mundial, ha sido más eficaz que el capitalismo caracterizado por un Estado limitado y un Banco Central constreñido, en vigor antes de la última guerra. La razón de esto se halla principalmente en que los déficit contracíclicos del capitalismo con Estado intervencionista han sostenido los beneficios, mientras que el Banco Central refinanciaba la estructura de las deudas y sostenía las organizaciones "insolventes" (Minsky, 1985:327).

En el marco del análisis de las crisis financieras, podemos establecer relaciones útiles con la teoría monetaria de Aglietta y Orléan (1982 y 2002). Ellos comparten con los poskeynesianos el rechazo por la teoría del trueque y por los fundamentos dicotómicos y explican la naturaleza monetaria de la economía por medio de las tensiones o la violencia, las cuales nacen de las relaciones de intercambio que la moneda permite apaciguar. Al instaurar confianza generalizada, ésta permite el reconocimiento social de la riqueza.

La unanimidad sobre un mismo objeto, al mismo tiempo que expresa la rivalidad más enorme, dado que cada uno se opone directamente a todos, ofrece una salida a los productores-comercializadores: el reconocimiento por toda una sociedad de una definición común de riqueza [...] Esta referencia común es producto de la violencia mimética. Ésta no es impuesta por el exterior por un deus ex machina poco probable, a la manera del secretario de mercado walrasiano; ésta es la consecuencia endógena del proceso mimético (Aglietta y Orléan, 2002:83).

De ese modo, la moneda es concebida como una convención social que permite a nuestro sistema tener una relativa estabilidad más que tender al caos.

La teoría de Aglietta y Orléan resulta particularmente esclarecedora para explicar los mecanismos que se desencadenan cuando sobrevienen las crisis financieras (Aglietta, 1988; Aglietta y Orléan, 2002). En efecto, si la moneda es un instrumento de pacificación de las relaciones económicas, es igualmente objeto de codicias; es, entonces, un factor de estabilidad e inestabilidad. El análisis de estos dos autores muestra el interés de los agentes por adoptar estrategias miméticas en el origen de fenómenos como profecías autocumplidas y de riesgo sistémico. "La ambivalencia del dinero" es de una naturaleza tal, que conduce a disfuncionamientos profundos de las economías monetarias; la moneda reside, de este modo, en el corazón de las crisis.

\section{Las variantes poskeynesiana y heterodoxa: similitudes y diferencias}

Hemos hablado de los elementos generales de una teoría de dinero endógeno basada en el análisis de Keynes de una "teoría monetaria de producción” y demanda efectiva, y ahora 
nuestra propuesta es discutir, aunque brevemente, algunos asuntos específicos relacionados con los poskeynesianos, pues también son del circuito monetario y la escuela cartalista. A pesar de las diferencias, podemos unir estas variantes más que separarlas. Por ejemplo, en gran medida las ideas discutidas están aceptadas por todas las variantes: la naturaleza endógena del dinero (al menos en algún grado), el análisis de Keynes de la demanda efectiva y el rechazo a la tasa de interés natural.

El debate entre horizontalistas y estructuralistas está enfocado esencialmente en dos relaciones específicas: el banco y los prestatarios, por un lado (la demanda para el crédito) y los bancos y el banco central (la demanda para dinero de alto poder), por el otro (por ejemplo, Rochon, 1999 y Lavoie, 1996 para una interpretación). Los bancos centrales son los "autores de precios y recipientes de la cantidad", y los préstamos crean depósitos, los cuales después crean reservas.

En el nivel del prestatario-banco, éste presta a todos sus clientes dignos de crédito; en el nivel de la banca-banco central, éste fija una tasa de interés y queda listo para proveer todas las reservas requeridas por la banca. Es decir, primero la banca presta y después les busca reservas, de ese modo, el banco central es el prestador del último recurso. Este último banco central jamás rechaza la oferta de reservas al sistema bancario, excepto en el caso en que planee aumentar la tasa de interés (Lavoie, 1996). Ello sugiere que el banco central puede fijar la tasa de interés en el nivel que desee, basado en sus objetivos domésticos. La tasa de interés es una variable puramente exógena, no es determinada en el mercado de dinero: es una variable distributiva (Rogers, 1989; Lavoie, 1992; Rochon, 1999). Así, los horizontalistas entienden la función de la oferta de dinero como una línea horizontal en el espacio tasa de interés/dinero, con implicaciones muy específicas. En particular, ahora la tasa de interés es independiente de la actividad económica; no hay motivo para creer que mientras la producción crezca, dicha tasa subiría.

Los estructuralistas, como Bob Pollin, Tom Palley y Randay Wray, rápidamente tomaron los argumentos presentados por Moore y otros horizontalistas para desarrollar una alternativa política monetaria poskeynesiana, enfocada en una curva de la oferta de dinero con inclinación ascendente, que incluye sus implicaciones y tiene que ver con los tres argumentos siguientes: primero, los bancos comerciales pueden decidir rechazar el crédito; segundo, el banco central también puede no cumplir con las necesidades de reservas del sistema de los bancos comerciales - Palley (1994:73-74) supone que una falta de acomodo del banco central implica que la "función de la oferta de préstamos también tendría una inclinación positiva"—; tercero, la expansión económica se dirige hacia cuentas más frágiles y a tasas de interés más altas, pues ésta no es independiente de la actividad económica. Según Pollin (1991:367): "Donde las dos versiones divergen es en [...] su explicación del proceso de "buscar las reservas después' ", que establece el banco central rotundamente en el centro del debate.

\section{DeSarrollo}


No obstante, hay un consenso entre los horizontalistas (Lavoie, 1996; Rochon, 1999) y los estructuralistas en los primeros dos argumentos. El asunto verdadero, creemos, fue en cuanto a las implicaciones de una falta de acomodo. Para los primeros, esto se tradujo en una tasa de interés más alta (una movimiento hacia arriba de la curva de oferta horizontal). Sin embargo, para los estructuralistas existió un efecto de "realimentación" de los depósitos a los préstamos o lo que Palley (1994:82) llama una "causalidad bivariada". Para Pollin (1991) y Palley (1991) una falta de acomodo resultó una reducción en los préstamos bancarios. En ese sentido, las reservas se ven como fuente de "fondos para el propósito del préstamo" (Palley, 1991:399): los bancos están racionados en el sentido neoclásico.

El último punto de diferencia es si la tasa de interés está ligada al ciclo comercial o no. El argumento estructuralista depende de una explicación en los niveles micro y macro. En el primero, mientras los bancos expanden sus préstamos y generan crecimiento, se convierten en menos líquidos y más riesgosos. En el segundo, mientras la economía se expande, también se convierte más frágil y ello sembrará las semillas de una desaceleración En los dos casos debe subirse la tasa de interés. No obstante, como ha demostrado Lavoie (1996), los bancos no necesariamente se convierten en menos líquidos o más riesgosos mediante un aumento en la extensión de préstamos: si continúan prestando a clientes meritorios de crédito, no hay motivo para suponerlo. Además, mientras la economía se expande, también genera utilidades y reduce la carga de deudas de las empresas. Como se puede apreciar, no hay una correlación necesaria entre los ciclos comerciales y el endeudamiento.

\section{La teoría del circuito monetario}

Los poskeynesianos también tienen gran afinidad con la teoría del circuito monetario. Respaldado por Alain Parguez, Bernard Schmitt y Augusto Graziani, todas las versiones franco-italianas aceptan la naturaleza endógena del dinero, la exógena de la tasa de interés, la importancia de la demanda efectiva y la necesidad lógica de pensar en la economía como una secuencia de eventos irreversible. Hay, sin embargo, diferencias entre ellos.

Su énfasis en la liga directa entre la formación y el uso del ingreso, por un lado, y la creación y destrucción del dinero, por el otro, es similar a la teoría poskeynesiana del dinero endógeno, y muchos poskeynesianos aceptan el mecanismo de la efluencia-refluencia en el cual están basadas la creación, circulación y destrucción del dinero bancario.

Como su nombre indica, la teoría del circuito monetario es, por lo tanto, primordialmente una explicación del flujo circular del dinero desde su creación por el sistema bancario hasta su destrucción por éste (Rochon, 1999; Lavoie, 1992; Realfonzo, 1999). Dicho flujo ocurre en tiempo lógico y los partidarios del circuito le separan en un número de fases en secuencia desde el inicio hasta su cierre.

La teoría del circuito monetario y la versión poskeynesiana comparten muchas características. Primero, los dos ponen énfasis en la importancia del crédito bancario para 
establecer y expandir el proceso de producción. Segundo, los poskeynesianos, así como los circuitistas favorecen un análisis parcial y secuencial de los fenómenos macroeconómicos, rechazando la búsqueda neoclásica para los equilibrios generales y simultáneos. Aunque el enfoque monetario poskeynesiano es acerca del tiempo y la incertidumbre y los otros aplican el papel macroeconómico de los diferentes clases de agentes, a ambos les interesan las relaciones parcial-total que afectan la demanda agregada y la distribución del ingreso en una economía monetaria de producción. Como resultado, los dos rechazan el individualismo metodológico e intentan construir una teoría macroeconómica que pueda explicar las formas observadas del comportamiento macroeconómico en términos de la causalidad en revés. Tercero, ambos consideran que la tasa de interés es una variable exógena que puede controlar el banco central.

\section{La teoría cartalista del dinero}

En años recientes, una nueva tradición ha aparecido en la escuela poskeynesiana. Los cartalistas, como se llaman (Lavoie se refiere a ellos como neocartalistas), han incorporado al análisis del dinero el papel central del Estado y el uso de los impuestos.

En reciente e importante contribución, Wray (1998) asevera que la existencia del dinero está directamente relacionada con la capacidad del Estado para establecer impuestos. Si el Estado es soberano, recolectará impuestos de sus ciudadanos en la ficha que considere apropiada. El público en general la usa porque es útil para pagarlos. Por ejemplo, en Estados Unidos, puesto que el gobierno demanda el pago de impuestos en dólares, éstos se convierten en la divisa de facto, implantada por el Estado. El dinero, según ese punto de vista, es una "criatura del Estado" y es "imposible de separar la teoría del dinero de la teoría del Estado" (Wray, op. cit.:23).

Si es imposible hacerlo, la versión cartalista también plantea que el dinero está inyectado en la circulación porque los ciudadanos demandan una divisa para pagar los impuestos que el Estado les requiere. Por eso la creación del dinero, o cómo el dinero está inyectado en circulación activa, está conectada con el Estado. Como éste es el "proveedor monopolista de la divisa", los ciudadanos tienen que venderle "bienes, servicios y activos" para recibir la divisa necesaria para pagar sus impuestos. Es decir, la política fiscal es el medio por el cual se inyecta el dinero en la circulación.

Respecto de la teoría poskeynesiana, se llega a dos importantes conclusiones. Primero, se debe notar que la versión cartalista es perfectamente compatible con el énfasis poskeynesiano acerca del dinero de cuenta. Segundo, la versión cartalista se considera compatible con el dinero endógeno y por eso critica tanto a la teoría de la ganancia convencional del Estado por acuñar el dinero (Wray, 2002), como a la teoría metalista (Goodhart, 1998). Mientras la primera propuesta es perfectamente clara, la segunda no es totalmente

\section{Desararrollo}


correcta (para una vista crítica de la teoría cartalista, véanse Rochon y Vernengo, 2003; Gnos y Rochon, 2002).

Según las versiones poskeynesiana y del circuito monetario, el dinero es primordialmente resultado de una relación de deuda entre dos agentes, los cuales pueden ser empresas productivas y bancos; el dinero se introduce al sistema económico al lado de la producción y del pago de salarios. La idea es que ésta no puede ocurrir sin un primer acceso a algún crédito bancario. Los bancos pueden extender el crédito (porque sus pasivos están aceptados como medio de pago) y no necesitan reservas previas para posibilitar préstamos: crean el dinero ex nihilo.

El dinero se inyecta en el sistema por los bancos y el requerimiento del crédito, no por el deseo del Estado de comprar "bienes, servicios y activos". De hecho, el Estado no puede comprar los bienes antes de que se produzcan, pues necesita que las empresas requieran el crédito para pagar salarios ex ante. Así, la producción precede al gasto del gobierno. El crédito bancario deben seguir siendo el enfoque central de una teoría del dinero endógeno.

De hecho, en los estudios de Wray, los bancos aparecen después en el análisis, pero su papel es mucho más secundario. A esto, el autor lo llama teoría horizontalista. Pero su componente es un claro argumento de segundo nivel. El punto de vista cartalista supone que en las sociedades modernas el Estado primero compra un bien del público en general y emite un cheque de su cuenta en Hacienda. El recipiente toma este cheque y lo deposita en su banco. En ese momento, hay una transferencia de fondos desde la cuenta del Estado hacia la cuenta del recipiente; así, los pasivos del banco comercial crecen. Después, el recipiente paga sus impuestos y la "diferencia neta entre estos dos flujos verticales (gastos deficitarios) dirige a una acumulación del dinero fiat "divisas en las manos del público general plus reservas bancarias" (Wray, 1998:111).

No obstante, el papel de los bancos es secundario, así como lo es el dinero de origen bancario. Dicho sector solamente puede dar apalancamiento a las acumulaciones monetarias. Según Wray (op. cit.:111): "El proceso de oferta de dinero bancario es horizontal; se puede pensar de un tipo de 'apalancamiento' de las acumulaciones del dinero fiat vertical". De ese modo, el dinero se inyecta al sistema mediante la política fiscal y el sector bancario da un apalancamiento a la oferta inicial exógena del dinero, lo cual incrementa el monto en circulación. En otras palabras, el dinero estatal es externo (exógeno), dinero fiat. Wray (ibid.:111-115) considera este modo como una integración de los puntos de vista verticalista y horizontalista.

Dicha integración con la bandera cartalista parece sorprendentemente familiar y no es por completo diferente del modelo del multiplicador monetario estándar de los escritores verticalistas más convencionales. Para los cartalistas, el dinero estatal es exógeno y el crediticio es múltiple del primero. Nosotros creemos que la diferencia básica entre poskeynesianos y cartalistas es el orden en el cual aparecen los argumentos verticalistas y 
horizontalistas. Para los cartalistas, el dinero es primeramente verticalista en su naturaleza, con dinero del banco en un papel secundario. Para los poskeynesianos, evidentemente es al revés: el dinero crediticio toma precedencia y es la fuerza primaria de la creación monetaria, mientras que el dinero fiat tiene papel secundario.

\section{Conclusión}

Los argumentos presentados en este trabajo nos permite concluir que con "la teoría poskeynesiana, disponemos de una explicación monetarizada no monetarista. Explicar la economía por medio de la moneda no conduce entonces obligatoriamente al modelo monetarista" (Goux, 1996:91).

En efecto, pudimos constatar que, al adoptar de antemano un análisis de la formación de los agregados en moneda - y rechazando los enfoques dicotómicos-, la teoría poskeynesiana resulta una herramienta útil para capturar el funcionamiento de nuestras economías monetarias. Si esta base teórica resulta eficaz para comprender la mecánica del sistema permite, asimismo, comprender la manera en la cual convendría regularlo, dado el caso. Al descomponer las relaciones entre las esferas financiera y productiva, los poskeynesianos brindan elementos esclarecedores y pertinentes para evaluar las consecuencias de una crisis financiera en el sistema en su totalidad.

Nos parece importante destacar que esta teoría se adecua perfectamente a una estructura de economía de mercado y no pregona una estatización completa o una renuncia a la libertad individual. Ésta simplemente pretende explicar el funcionamiento y la disfunción de esas economías. ${ }^{19}$ Se trata, sobre todo, de comprender cómo las fuerzas de mercado dejadas a su libre expresión pueden a veces sumergir al sistema en una crisis. Podemos concebir que, en ciertos casos, más que llevar al sistema a una situación de equilibrio, estas fuerzas naturales lo alejan. Para retomar la bella metáfora de Fisher, es posible que "cuanto más se inclina el buque de la economía, más tiende a inclinarse. Éste no tiende a corregir su eslora sino que, por el contrario, se está hundiendo" (1933/1988:173).

Ha sido evidentemente el caso de la crisis de los años treinta, con el derrumbe de las estructuras financiera y productiva y sus consecuencias sociales trágicas. Algunas enseñanzas han surgido de ese dramático episodio. No obstante, si las crisis necesariamente no degeneran, lamentablemente resulta posible que lo hagan, como nos lo recuerda la reciente y cruel experiencia argentina. En momentos en los cuales la globalización y la liberalización financieras se acompañan de una creciente volatilidad, la advertencia de Minsky resuena con sorprendente actualidad: "si la ortodoxia presupuestaria y la no intervención del Banco Central características de los años veinte se convierten algún día en la política del gobierno estadounidense y de la Reserva Federal, entonces una crisis como la de mediados

19 Es una característica común de todos los análisis keynesianos. 
de 1982 puede conducir a algo muy parecido a la tragedia de los años treinta. Si ésto se produce, habrá que sacar nuevamente las conclusiones que sacó Keynes de su estadía en Chicago" (Minsky, 1985:327-328). Parece evidente que la agudeza de esta advertencia resuena mucho más allá de la economía estadounidense. Los análisis desarrollados por los poskeynesianos justamente permiten entender, por un lado, la necesidad de promover una regulación del sistema monetario y financiero y, por otro, en caso de crisis, entender los riesgos incurridos en "dejar librada al azar la iniciativa de la recuperación" (Fisher ,1933/ 1988:176). En el contexto actual, hacer oídos sordos sería una actitud peligrosa. Esperemos que acordándoles una audiencia más importante, sus advertencias —derivadas de las enseñanzas de Keynes- encuentren el eco que merecen.

\section{Bibliografía}

Arena, R., "Monnaie, production et actifs financiers dans une perspective keynésienne: quelques éléments d'interprétation", en Économies et Sociétés, t. XVIII, núm. 4, 1984, pp. 259-282

_ _ y D. Torre, Keynes et les nouveaux keynésiens, Niza, PUF, 1992.

Aglietta, M., "L'ambivalence de l'argent", Revue française d'économie, vol. 3, núm. 3, 1988, pp. 87-133.

y A. Orléan, La violence de la monnaie, París, PUF, 1982.

, La monnaie entre violence et confiance, París, Odile Jacob, 2002.

Baranzini, M. y A. Cencini (editores), Inflation y Unemployment. Contributions to a New Macroeconomic Approach, Londres, Routledge, 1996.

Barrère, A. (editor), Économie réelle-Économie monétaire, Économie Appliquée, t. xxxvIII, núm. $1,1985$.

- Macroéconomie keynésienne, París, Dunod, 1990.

Baumol, W.J., "La demande de liquidités en vue des transactions abordée par la théorie de l'inventaire", en R.S. Thorn, Théorie monétaire, París, Dunod, 1971, pp. 138-152.

Bradley, X.; P. Piégay y S.Rossi, "Taux d'intérêt et "propriétés fondamentales" de la monnaie", en P. Piégay y L.-P. Rochon, Théories monetaires post keynesiennes, París, Economica, 2003, pp. 226-242.

Brossard, O., "L'instabilité financière selon Minsky: l'incertitude et la liquidité au fondement du cycle?", en Revue Économique, vol. 49, núm. 2, 1998, pp. 407-435.
Cencini, A., "Micro, macro et l'analyse du circuit", en P. Piégay y L.-P. Rochon, Théories monetaires post keynesiennes, París, Economica, 2003, pp. 209-225.

Cottrell, A., "Post-Keynesian Monetary Theory", en Cambridge Journal of Economics, vol. 18, núm. 6, 1994, pp. 587-605.

Davidson, P., Money and the Real World, Londres, Macmillan, 1972.

_ _ "Rational Expectations: a Fallacious Foundation for Studying Crucial DecisionMaking Processes", en Journal of Post Keynesian Economics, invierno de 1983, pp. 182-198.

__ , "L'économie post-keynésienne, solution à la crise de la théorie économique", en D. Bell e I. Kristol, Crise et renouveau de la théorie économique, París,Bonnel Publisud, 1986, pp. 251-281.

_ , "Quels sont les éléments essentiels de la théorie monétaire post-keynésienne?", en P. Piegay y L.-P. Rochon, Théories monetaires post keynesiennes, París, Economica, 2003, pp. 19-40.

Deleplace, G., "Des hétérodoxies diverses", en Histoire de la pensée économique: du 'royaume agricole' de Quesnay au 'monde à la ArrowDebreu', París, Dunod, 1999, pp. 433-79.

- y E.J. Nell, "Introduction: Monetary Circulation y Effective Demand", en G. Deleplace y E.J. Nell (editores), Money in Motion. The Post Keynesian y Circulation Approaches, Londres, Macmillan, 1996, pp. 3-41.

Delong, B., "How to Teach Monetary Policy: do Central Banks Set the Interest Rate, or do They Target the Money Stock?", documento de trabajo,

\section{Desarrollo}


2001,www.j-bradford-delong.net/macro_online /interest_rates_ms.html.

Diatkine, S., "La théorie post-keynésienne, la "Théorie Générale" et Kalecki: quelques réflexions complémentaires", en P.P. Maurisson, La "Théorie Générale" de John Maynard Keynes: un cinquantenaire, Cahiers d'économie politique, núm. 14-15, París, L'Harmattan, 1988, pp. 143-149.

- Théories et politiques monétaires, París, A. Collin, 1995.

Dostaler, G., "La théorie post-keynésienne, la "Théorie Générale" et Kalecki”, en P.P. Maurisson, La "Théorie Générale" de John Maynard Keynes: un cinquantenaire, Cahiers d'économie politique, núm. 14-15, París, L'Harmattan, 1988, pp. 123-142.

Dupuy, J.-P. et al., "L'économie des conventions", en Revue Économique, vol. 40, núm. 2, 1989.

Favereau, O., "Probability and Uncertainty: After All, Keynes Was Right", en Économies et Sociétés, t. XXII, núm. 10, 1988, pp. 133-167.

Fisher, I., "La théorie des grandes dépressions par la dette et la déflation", en Revue Française d'Économie, vol. III, núm. 3, 1933/1988, pp. 159-182.

Fontana, G., "Post Keynesians y Circuitists on Money and Uncertainty: an Aattempt at Generality", en Journal of Post Keynesian Economics, vol. 23, núm. 1, 2000, pp. 27-48.

Gnos, C., "Circuit Theory as an Explanation of the Complex Real World", en L.-P. Rochon y S. Rossi (editores), Modern Theories of Money. The Nature y Role of Money en Capitalist Economies, Cheltenham, Edward Elgar, 2003, pp. 322-338.

y L.P. Rochon, "Money Creation y the State: A Rejoinder to Chartalism (or Chartalism within the Theory of the Monetary Circuit)", en International Journal of Political Economy, vol. 32, núm. 3, otoño de 2002, pp. 41-57. , "Joan Robinson y Keynes on Money, Relative Prices y the Monetary Circuit", en Review of Political Economy, vol. 15, núm. 4, 2003.

Goodhart, Charles A.E., "The Two Concepts of Money: Implications for the Analysis of Optimal Currency Areas", en European Journal of Political Economy, núm. 14, 1998, pp. 407-32.

Goux, J.-F., "Une explication monétaire non monétariste: la théorie post-keynésienne", en Revue Française d'Économie, vol. xI, núm. 3, 1996, pp. 69-94.

Graziani, A., "The Theory of the Monetary Circuit", en Économies et Sociétés, vol. xxIv, núm. 6, 1990, pp. 7-36.

, "Microéconomie et macroéconomie: à qui la priorité?", en P.P. Piégay y L.-P. Rochon,
Théories monetaires post keynesiennes, París, Economica, 2003, pp. 121-128.

Kaldor, N., "The New Monetarism", en Lloyds Bank Review, julio de 1970, pp. 1-7.

, Le fléau du monétarisme, París, Economica, 1985.

_ y J. Trevithick, "A Keynesian Perspective on Money", en Lloyds Bank Review, vol. 139, enero de 1981, pp. 1-19.

Keynes, J.M., "Festschrift für Arthur Spiethoff (1933): a Monetary Theory of Production", en The Collected Writings of John Maynard Keynes, vol. xIII, 1933/1973a, pp. 408-411.

, "The General Theory of Employment", en The Collected Writings of John Maynard Keynes, vol. xIv, 1937/1973b, pp. 109-123.

, "A Treatise on Probability", en The Collected Writings of John Maynard Keynes, vol. viI, Londres, Macmillan, 1921/1973.

-, "A Treatise on Money. The Pure Theory of Money", en The Collected Writings of John Maynard Keynes, vol. v, Londres, Macmillan, 1930/1971.

, Théorie générale de l'emploi, de l'intérêt et de la monnaie, París, Payot, 1936/1969.

-, "The General Theory y After, Part I preparation", en The Collected Writings of John Maynard Keynes, vol. XIII, Londres, Macmillan, 1973a.

, "The General Theory y After, Part II defence y development", en The Collected Writings of John Maynard Keynes, vol. XIV, Londres, Macmillan, 1973b.

, "Activities 1940-46: Shaping the post-War World, The Collected Writings of John Maynard Keynes, vol. xxvII, Londres, Macmillan, 1945/ 1980.

King, J., A History of Post Keynesian Economics Since 1936, Cheltenham, Edward Elgar, 2002.

Lavoie, M., "Un modèle post-keynésien d'économie monétaire fondé sur la théorie du circuit", en Économies et Sociétés, vol. 18 , núm. 2, 1984, pp. 233-58.

, "Monnaie et production: une synthèse de la théorie du circuit", en Économies et Sociétés, vol. xxi, núm. 9, 1987a, pp. 65-101.

_- Macroéconomie: théories et controverses post-keynésiennes, París, Dunod, 1987b.

- Foundations of Post-Keynesian Economic Analysis, Aldershot, Edward Elgar, 1992.

, "A Primer on Endogenous Money", en L.-

P. Rochon y S.Rossi (editores), Modern Theories of Money. The Nature y Role of Money en Capitalist Economies, Cheltenham, Edward Elgar, 2003, pp. 506-543.

, L'économie postkeynésienne, París, $\mathrm{La}$ Découverte, 2004a.

\section{DeSarrollo}


_ "The New Consensus on Monetary Policy Seen from a Post-Keynesian Perspective", en M. Lavoie y M. Seccareccia (editores), Central Banking en the Modern World: Alternative Perspectives, Cheltenham,Edward Elgar, en preparación, 2004b.

, "A Post-Keynesian Amendment to the New Consensus on Monetary Policy", en Metroeconomica, en preparación, 2005a.

_, "Monetary base endogeneity y the new procedures en the asset-based Canadian y American monetary systems", en Journal of Post Keynesian Economics, en preparación, 2005b.

Le Bourva, J., "La théorie de l'inflation, le rapport des experts et l'opération de décembre", en Revue économique, vol. 10, núm. 5, 1959, pp. 713754.

Markowitz, H.M., Portfolio Selection, Nueva York, Willey, 1959.

Mccallum, B., "Monetary Policy Analysis en Models without Money", en Federal Reserve Bank of St. Louis, julio-agosto de 2001, pp. 145-160.

Meyer, "Does Money Matter?", en Federal Reserve Bank of St. Louis, septiembre-octubre de 2001, pp. 1-15.

Minsky, H.P., "La structure financière: endettement et crédit", en A. Barrère, Keynes Aujourd'hui: théories et politiques, París, Economica, 1985, pp. 309-328.

$\longrightarrow$, Stabilizing an Unstable Economy, , New Haven, Yale University Press, 1986.

Moore, B.J., Horizontalists y Verticalists. The Macroeconomics of Credit Money, Cambridge, Cambridge University Press, 1988.

,"Some reflexions on endogenous money", en L.-P.Rochon y M. Vernengo (editors), Credit, Interest Rates y the Open Economy, Cheltenham, Edward Elgar, 2001, pp. 11-30.

Nasica, E., "Comportements bancaires et fluctuations économiques: 1'apport fondamental d'H.P. Minsky à la théorie des cycles endogènes et financiers", en Revue d'Économie Politique, vol. 107, núm. 6, 1997, pp. 853-873.

Orléan, A., Analyse économique des conventions, París, PUF, 1994.

Palley, T., "The Endogenous Money Supply: Consensus y Disagreement", en Journal of Post Keynesian Economics, Spring, vol. 13, núm. 3, 1991, pp. 397-403.

-, "Competing Views of the Money Supply Process: Theory y Evidence", en Metroeconomica, vol. 45, núm. 1, 1994, pp. 67-88.

Parguez, A., "Beyond Scarcity: A Reappraisal of the Theory of the Monetary Circuit", en G. Deleplace, y E. Nell (editores), Money en Motion, Londres, Macmillan, 1996.
- y M. Seccareccia, "The Credit Theory of Money: the Monetary Circuit Approach", en J. Smithin (editor), What is Money?, Londres, Routledge, 2000, pp. 101-123.

Piégay, P.P., "The New y Post Keynesian Analyses of Bank Behavior: Consensus y Disagreement", en Journal of Post Keynesian Economics, vol. 22, núm. 2, 2000, pp. 265-283.

____, "Offre de monnaie endogène et comportement bancaire: une interprétation des controverses post-keynésiennes", en Économie Appliquée, t. LIV, núm. 4, 2001, pp. 79-94.

- y L.-P. Rochon, Théories monetaires post keynesiennes, París, Economica, 2003.

Pollin, R., "Two Theories of Money Supply Endogeneity: Some Empirical Evidence", en Journal of Post Keynesian Economics, Spring, vol. 13, núm. 3, 1991, pp. 366-395.

Realfonzo, R., "French Circuit School", en P.A. O'Hara (editor), Encyclopedia of Political Economy, vol. I, Londres y Nueva York, Routledge, 1999, pp. 375-378.

Robinson, J., The Accumulation of Capital, Londres, Macmillan, 1956.

Rochon, L.-P., “Keynes's Finance Motive: A ReAssessment. Credit, Liquidity Preference y the Rate of Interest", en Review of Political Economy, vol. 9, núm. 3, 1997, pp. 277-293.

, Credit, Money y Production. An Alternative Post Keynesian Approach, Cheltenham, Edward Elgar, 1999.

_ , "The Creation and Circulation of Endogenous Money: a Circuit Dynamique Approach", en Journal of Economic Issues, vol. 33, núm. 1, 1999a, pp. 1-21.

—, "Wicksell After the Taylor Rule: A PostKeynesian Critique of the Taylor Rule", Laurentian University, mimeografiado, 2004.

_ - "Joan Robinson on Credit, Money y Production: A Forgotten Contribution", en W. Gibson (editor), The Economic Legacy of Joan Robinson, Cheltenham, Edward Elgar, 2005.

___ A Post Keynesian Theory of Credit Constraint: A Horizontalist Perspective, Nueva York, Eastern Economic Association, 2005a.

__ y S. Rossi, "Central Banking en the Monetary Circuit", en M. Lavoie y M. Seccareccia (editores), Central Banking en the Modern World: Alternative Perspectives, Cheltenham: Edward Elgar, 2004.

, Evolutionary y Revolutionary Views of Money: The Post-Keynesian Theories of Endogenous Money, Nueva York, Eastern Economic Association, 2005.

- y M. Vernengo, "La monnaie d'État et le monde réel: le malaise du chartalisme", en P.P. 
Piégay y L.-P. Rochon (editores), Théories monetaires post keynesiennes, París, Economica, 2003, pp. 177-188.

Rogers, C., Money, Interest y Capital. A Study en the Foundations of Monetary Theory, Cambridge, Cambridge University Press, 1989.

Rotheim, R.J. (editors), New Keynesian Economics/ Post Keynesian Alternatives, Londres, Routledge, 1998.

Sawyer, M., "Kalecki, Keynes et l'analyse postkeynésienne de la monnaie", en P.P. Piégay y L.-P. Rochon (editores), Théories monetaires post keynesiennes, París, Economica, 2003, pp. 8398.

Schmitt, B., La formation du pouvoir d'achat, París, Sirey, 1960

, Monnaie, salaires et profit, París, PUF, 1966.

, Inflation, chômage et malformations $d u$ capital, París, Economica, 1984.

Seccareccia M., "Post-Keynesian Fundism y Monetary Circulation", en G. Deleplace y E.J. Nell (editores), Money in Motion. The Post Keynesian y Circulation Approaches, Londres, Macmillan, 1996, pp. 400-416.

Shackle, G.L.S., Uncertainty en Economics, Cambridge, Cambridge Univestity Press, 1955.
Smithin, J., Controversies en Monetary Economics: Ideas, Issues y Policy, Cheltenham: Edward Elgar, 2003.

, “Optimal Monetary Policy?”, en M. Lavoie y M. Seccareccia (editores), Central Banking en the Modern World: Alternative Perspectives, Cheltenham, Edward Elgar, en preparación, 2004.

Tobin, J., "The Interest Elasticity of Transactions Demand for Cash", en The Review of Economics y Statitics, vol. xxxvIII, núm. 3, 1956, pp. 241-247.

, "La préférence pour la liquidité en tant que comportement face au risque", en R.S. Thorn (editor), Théorie monétaire, París, Dunod, 1971, pp. 153-182.

Weintraub, S., "Money-Demand Motives: a Reconsideration", en Économie Appliquée, vol. xxxv, núm. 3, 1982, pp. 361-376.

Wolfson, M.H. [1996], "A Post Keynesian theory of credit rationing", en Journal of Post Keynesian Economics, vol. 18, núm. 3, , 1996, pp. 443-470.

Wray, L.R., Understanding Modern Money: The Key to Full Employment y Price Stability, Cheltenham y Northampton, Edward Elgar, 1998. , “Seigniorage y Sovereignty?", en L.-P. Rochon y S. Rossi (editores), Modern Theories of Money. Cheltenham, Edward Elgar, 2002.

\section{DeSarrollo}

